\title{
A writer's suicide: On creativity, mental health, gender and ethics
}

\author{
URMILA G
}

\begin{abstract}
The correlation between creativity and mental illness has been at the centre of ongoing debates for quite some time. This has its roots in the Romantic era (late 18 th to mid-19th century), when melancholia and madness were considered to be the signs of creativity and genius. Because of this, writers like Virginia Woolf, Sylvia Plath, Anne Sexton, Charlotte Perkins Gilman, and many other prominent creative minds have been represented in popular narratives as having reached the heights of their creative careers while struggling with their mental health. This paper addresses the need for moving away from Romantic era notions of the relationship between madness, genius, and melancholia that reinforce the inseparability of the writer and the text, thereby trivialising the real causes and effects of mental illness.

The paper also addresses the need for a health humanities intervention within the Indian literary public, using examples from the existing narratives on the late Malayalam writer Rajelakshmy - an established woman writer in the 1960s who died by suicide in her mid-thirties. This paper will also reflect on the author's own experience of reading and working with Rajelakshmy's writings over the years.
\end{abstract}

Keywords: Women writing, Malayalam literature, gender, mental health, medical humanities,

TA Rajelakshmy, the first Malayalam woman writer to receive the Kerala Sahitya Academy Award, died by suicide on January 18,1965 . She hanged herself with a saree from the ceiling of her rented house in Ottapalam, a city in the district of Palakkad, Kerala. In her suicide note written to her elder sister, she wrote: "I lived without writing for the past two

Author: Urmila G (urmila.g@learner.manipal.edu), PhD Scholar, Manipal Centre for Humanities, Manipal Academy of Higher Education (MAHE), Alevoor Road, Manipal, Karnataka, 576104 INDIA

To cite: Urmila G. A writer's suicide: On creativity, mental health, gender and ethics. Indian J Med Ethics. Published online on August 30, 2021. DOI: 10.20529/IJME.2021.066

Manuscript editor: Rakhi Ghoshal

Peer Reviewer: Sunil K Pandya and an anonymous reviewer.

(c) Indian Journal of Medical Ethics 2021 years. I cannot do this. If I remain, I will have to write. I do not know who all will be hurt by it. So, let me leave." (1). Rajelakshmy, who had a very short literary career (1950s1960s), had, nevertheless, been a celebrated author in Kerala. The literary culture of women writing on women's spaces in Kerala began with writer Lalithambika Antharjanam in the late 1920s. Rajelakshmy, who entered the literary sphere in the 1950s, attempted to reflect on the concerns of the newly educated and employed middle class female workforce, through her fiction. Rajelakshmy's female protagonists are often clerical officers, teachers, lawyers, and researchers-all exhausted by the tussle between the domestic and the public spheres, and struggling to fulfil their assigned duties and obligations as women.

Rajelakshmy's oeuvre consisted of twelve short stories; two poems titled Kumila (Bubble) and Ninne Njan Snehikkunnu (I Love You); two novels, Oru Vazhiyum Kure Nizhalukalum (A Path and Many Shadows, 1958) and Njanenna Bhavam (Ego, 1965); and an unfinished novel Uchaveyilum Ilam Nilavum (The Noon Sun and the Tender Moonlight, 1960).

In 1949, she received a BSc in Physics and the same year she also published her first short story titled Hostel Mate, in the widely read magazine Mathrubhumi (Motherland). She received her MSc in Physics from Banaras University, Varanasi, in the year 1953, after which she worked as a college lecturer at different institutions across Kerala. Her second short story (also her longest), Makal (Daughter) came out in 1956 and immediately attracted the attention of readers. NV Krishna Warrier, the editor of Mathrubhumi weekly magazine at the time, wrote a posthumous tribute to the writer titled "Rajelakshmy Enna Ezhuthkari" (Rajelakshmy, the Writer). In the tribute, Warrier shares his experience of reading the manuscript of Makal for the first time, and he writes, "I have read somewhere about the thrill that an astronomer scanning the vast skies experiences at the sight of a new star moving towards him in the telescope. It was a similar thrill that I, a journalist leading an otherwise dreary existence, experienced on reading Rajelakshmy's outstanding work" (2). However, many of her family and friends thought they saw themselves in several of the characters within the story, and severely criticised her (1). While her second novel The Noon Sun and the Tender Moonlight was being serialised in Mathrubhumi magazine (1960), Warrier received several letters asking him to stop the publication of this novel. Rajelakshmy, who was 
extremely distressed by this feud with her family and friends, retrieved the unprinted copy of the novel, and is said to have burned it herself. Warrier, who read the complete manuscript of the novel, wrote that if it had been published after completion, it would have been Rajelakshmy's finest fictional work (2).

The unexpected early demise of such a talented woman writer was a shock to the public. In addition, the mystery behind the death of a female writer, who was an unmarried woman in her mid-thirties, was a matter of great intrigue in the 1960s. Eminent Malayalam novelist MT Vasudevan Nair, Rajelakshmy's contemporary, wrote, "A section of society that compassionately understands the dilemmas of the writer, the mental restlessness and complex pains that work as a background for literary creation, did not provide shelter for her. If an artist, either man or woman, who has a heart too tender to be tossed even by a gentle breeze, is forced to write out the last chapter of life, the mercilessness of that section of society which served as backdrop stands stigmatized." (3). Even though it was a heartfelt note about the death of a contemporary, one cannot ignore how he describes Rajelakshmy's mental state as "too tender" and her predicament as a mere "gentle breeze". MT Vasudevan Nair was not the only person to address Rajelakshmy's suicide in this manner. Several writers and critics of the time even offered unsolicited analyses drawing upon the traits of the characters in Rajelakshmy's writings and her own disposition, which was itself dissected repeatedly on public forums. Many had come to the conclusion that Rajelakshmy took her own life because of some entrenched personal defect, and that it could be ascertained from her writings. Some writers and critics at the time even went on to tell tales of a "sick mind" that they claimed to have found hidden in her writings, and concluded this to be the reason for her purportedly unsuccessful literary career and even for her suicide (2).

This paper addresses the need for a health humanities intervention within the vernacular literary public, on the need for moving away from Romantic era notions of the relationship between madness, genius, and melancholia. It will also look at the need for separating the writer and the text and will address the gendered nature of the criticisms that prevail in literary circles when it comes to issues concerning mental illness which often assigns a predetermined trajectory to the writer's literary career and personal life-a distinction that is also largely ignored. Such approaches also dismiss the idea of the individuality of a literary work and trivialise the real causes and effects of mental illness. Finally, this paper also uses the example of Rajelakshmy and will reflect upon my own experiences of reading and working with her writings over the years.

\section{Melancholia and Rajelakshmy's writings}

Even today, the narratives around Rajelakshmy's life and her writings evoke the trope of a lonely woman. The image of a "solitary traveller" has repeatedly been used by Malayalam writers and critics while analysing the disposition of characters in Rajelakshmy's writings. MT Vasudevan Nair in his tribute to the writer titled Ekanthapathika (Lonely traveller1965), uses the term "spiritual isolation" to describe the melancholy atmosphere in the writings of Rajelakshmy, comparing it to that of modernist writer Virginia Woolf (18821941) (4). Woolf's history of mental illness is a widely known fact and there was even a time when it was romanticised by the literary public. She suffered from bipolar disorder-which was called "manic depression" at the time-and had been treated for her illness multiple times until her eventual suicide in 1941. Since her suicide, there have been several morbid psychoanalytic analyses of Woolf's life, sexuality, mental health, and suicide, in relation to her literary creations. Roger Poole in The Unknown Virginia Woolf writes that the creeping feeling of "guilt" and "failure" that the protagonist Mrs Dalloway (from the eponymous novel) experiences can be explained from the depiction of Woolf as a "damaged thing, a spoilt, wingless bird" (5). In another study, in the book The Flight of the Mind: Virginia Woolf's Art and Manic-Depressive Illness (1992), author Thomas C Caramagno, drawing from the scientific study on manic-depressive illness, attempts to critique the outdated Freudian model of viewing the illness or the disorder as a neurotic dispute that the sufferer is either consciously or unconsciously hesitant to overcome. He goes on to argue against "the arbitrary and subjective practice of reading all symptoms or [Woolf's] texts as neurotic disguises supposedly obscuring a causative origin" (6). His analysis states that within such a Freudian understanding is the unsaid or even unconscious reading that Woolf became a writer because she was mentally ill and that her "books are filled with references to death and strange desires for a depersonalized union with the cosmos because, like all neurotics, she was afraid to live fully" (6). Similarly, when writer MT Vasudevan Nair writes about the solitariness reflected in the life and works of Rajelakshmy or Woolf, he is also referring to their creative state of mind as lonely, and therefore, creative, which is in many ways a highly gendered approach towards both creativity and mental illness.

The correlation between creativity and mental illness has been at the centre of an ongoing debate, which has its roots in the Romantic era, when melancholia and madness were considered to be the signs of creativity and genius. Hence, literature itself has a very distinct connection with mental illness, for it also arose from its fascination with melancholia (7). Psychologist James C Kaufman coined the term "Sylvia Plath Effect" (2001) in his study of famous writers and their mental health, where he concludes that female poets are more susceptible to mental illness compared to other writers (8). Poet and novelist Sylvia Plath (1932-1963) was also clinically depressed. She is known to have attempted suicide several times and finally succeeded in 1963. Other than Virginia Woolf and Sylvia Plath, many other prominent female creative minds of the time such as Anne Sexton and Charlotte Perkins Gilman have been represented in popular narratives as reaching the heights of their creative career while 
struggling with their mental health.

It is precisely the pervasiveness of such popular narratives that admittedly attracted me initially to Rajelakshmy's writings, more than the fact of her being the first woman to win the Kerala Sahitya Academy Award. During the course of my under-graduate studies in Kerala, Rajelakshmy was not as popular as her contemporaries Lalithambika Antharjanam or Madhavikutty. The only aspect of Rajelakshmy's literary career that every literary enthusiast was familiar with was her suicide. In my first reading of her works, I forcefully saw the reflection of a lonely writer in the pensive sadness of each of her characters. When Sarada in her short story Daughter felt lonely in her large family, I read it as the reflection of Rajelakshmy's imagination and artistic temperament, influenced by her personal experiences. It was only during my postgraduation years that I came to understand how distorted such an approach was, and how unfair it was to the writer and the text.

\section{Rereading Rajelakshmy}

Writer K Saraswathi Amma, a feminist contemporary of Rajelakshmy, in her only novel Premabhajanam, portrays the suicide of the female protagonist Louisa as a deliberate, planned move, against the patriarchal social structure. Through Louisa's prearranged "performance" or act of resistance "a social message is conveyed" (9). Such a reading showcases how suicide is in fact a complex matter and at times the mental illness caused by the lack of timely assistance cannot be the sole reason for it. However, the mystery behind Rajelakshmy's suicide made the audience draw a direct correlation between her fictional character's dejected mental state and her own personality-an approach that was mostly gendered and in complete disregard of the writer's own mental state and predicament. This is evident in the newly translated anthology of the author titled A Path and Many Shadows and Twelve Stories. More than half a century after the death of the author, Rajelakshmy's works, which were only available in Malayalam till then, have been translated and published as an anthology, under the translation project of Thunchath Ezhuthachan University in 2016. This book consists of twelve short stories and a novel with an introduction titled "Rajelakshmy, The Tale and the Teller," written by bilingual writer and critic PP Raveendran. There is little scholarship on Rajelakshmy's writings even now, and therefore, Raveendran's introduction to the book is crucial. A section of his introduction discusses the distinct approaches that a few male critics and writers had taken while evaluating Rajelakshmy as a writer of contemporary relevance. These critics characterised Rajelakshmy as a writer who could not reach the pinnacle of her creative career because of a purported deep character flaw, also assumed to be the eventual cause of her suicide (2). Among them, D Benjamin wrote that while, Rajelakshmy's stories cannot, in "terms of craftsmanship, claim the structural compactness of the short stories of MT Vasudevan Nair or T Padmanabhan, they are remarkable for the spontaneity of self-expression" (2). Yet another criticism was that though Rajelakshmy's writings are "expressive of subjective emotions and experiences unique to her personality, they lack refinement because of the author's temperamental insufficiency and inability to connect with the external world" (2). This criticism again is rooted in the Romantic era notion that "genius" is a masculine trait and thus, attributing creativity only to male writers (10).

While the popular notion behind the term "mad genius" is always ascribed to a male writer, the ingenuity of a female writer is often read as the reflection of her sadness or even wildness. Male writers are exempted from such personal readings and are celebrated for their creativity. Cultural historian J Devika, in her book Womanwriting = Manreading?, writes that in Kerala, a female writer could be called a writer par excellence only if she separated her writings from her immediate surroundings and life struggles. It is to be noted that the literary public never conceded to a woman writer the "plurality of self" since supposedly there is no separation for her as a woman who lives with other capabilities and as a "woman who writes" (10). Writer Rajelakshmy was also not allowed such a plurality. The aesthetic fascination with the writer's death was, and continues to be, a persisting criticism where her writings are read as an early premonition of her eventual suicide (3). Eminent Malayalam critic and writer KP Appan uses the phrase "death's poignant premonition" (maranathinte hridyamaya munnariyippukal) as a metaphor to depict what Raveendran calls the "bleak and sombre" ambience permeating her writings (2). These approaches to reading a female writer's writings are problematic in two ways: they (i) diminish the concept of individuality of an artistic creation, and (ii) minimise the seriousness of the real conditions of any mental illness (7). Understanding Rajelakshmy's writings based on such an approach has evidently devalued the integrity of the feminist content she had created in mid-twentieth century Kerala. She is one of the early writers in Malayalam literature to introduce the perspective of the newly emergent modern, educated and employed woman in her fictional works. Her characters, untying themselves from the domestic space, and appearing in working spaces, were intended to dispel the illusions of the female literary public that with their entry into the workspace they were being liberated from traditional patriarchal structures. Instead of the social commentary in her narratives, critics have focused on finding instances of melancholia in her writings to justify their conservative preconceptions pertaining to creativity, mental health and women's writing.

\section{A medical humanities approach}

It was in 2016 that I was introduced to the discipline of medical humanities which emphasised the importance of shifting the language while engaging with narratives of the body and illness. The scholarship focused heavily on shattering the binaries of sanity and insanity, normal and abnormal, health and disease, and many other commonly held assumptions about illness. This course provided an 
entirely new perspective of illness and writing about illness to a batch of postgraduate students who had been studying literature for the past couple of years. A close analysis of different narratives of the body and illness also gave students a safe platform to share their own perspectives and experiences of coping with illness. This course in many ways made me approach Rajelakshmy and the various criticisms levied against her writings through a new lens. The prominent frameworks for reading Rajelakshmy's writings provide an example of how the tendency to write biographical post-mortems ought to be resisted. Thomas $C$ Caramagno writes that "as academics, we are in the business of proving our mastery over material and ourselves; perhaps that is why we are ungenerous toward those artists who show less control. But when we unthinkably blame the victim for his/her illness, we simplify our work by ignoring the mind/ brain nexus from which everything most human about literature arises." (6).

There have been recent studies that question whether there is a "Rajelakshmy Effect" in Malayalam literature similar to the western study on the "Sylvia Plath Effect." (11) These are precisely the kinds of approaches that must be resisted. Such correlational studies again invite the debate surrounding creativity and mental illness, which could lead to a psychiatric study of the subject's mental disorders and thus derail the possibility of separating the author (typically female) from her fiction. To clarify, the suggestion here is not that we stop reading into illness from all mental health narratives. My argument is that we should restrict the practice of reading into the author's struggle with mental illness and using that as the entry point into her writings, thereby limiting the author herself within the boundaries of psychopathology.

In the context of teaching Health Humanities to medical students, writer and literary scholar Gayathri Prabhu discusses how exposure to an effective Humanities education will enhance the critical thinking of aspiring young medical students. She writes on how this will aid medical students in "reading/listening to various health narratives," and also how it will offer them the "possibilities of understanding ethics as a broader worldview" (12). As was discussed previously, there are studies on writer Virginia Woolf that critique the way the Freudian approach has manipulated several studies on her illness and works over the years. We need similar interventions in Indian literature as well. An intervention of an interdisciplinary medical humanities pedagogy within the Indian Humanities scholarship will instil in students the need for an ethical approach to suffering and its articulation while reading works of authors like Rajelakshmy. There is a need for reading texts with deliberate caution, and for separating the writer's biography from the text and seeing the text as a separate entity of its own. For this, one has to move away from the influential Romantic era notions of madness, genius, and melancholia which are still predominant within literary circles and popular culture. Such influences also come from the stigma surrounding mental illness and of the negative portrayal of characters with mental illness in popular culture, which is equally, if not more, ridden with these notions. A recent Malayalam film Kumbalangi Nights (directed by Madhu C Narayanan, 2019) initiated a conversation about mental illness through its lead character's depression. In the film, the character Saji (played by Soubin Shahir), a young jobless man living with his brother in the eponymous fishing village, asks his younger brother to take him to a psychiatrist when he realises that he needs help. Saji is portrayed as benefitting from therapy. The image of Saji is now being used by health departments in Kerala during the Covid-19 pandemic, to increase awareness and remove the stigma surrounding mental illness, thereby encouraging citizens to ask for help when needed. This shows that while the intervention of medical humanities is necessary within academia, popular culture must also be used consciously and effectively to develop an ethical standard for mental health narratives. While moving away from the influences of pre-existing notions on "mad genius" or "melancholia" in literature is significant for an ethical analysis of writings, the popular literary culture should also engage in eradicating such beliefs, so that a more sensitive and scientific approach could be employed while engaging with mental illness and writings about it.

\section{References}

1. Gramaprakash NR. Ekanthapathika: Rajalakshmi Jeevithavum Ezhuthum. Kottayam: Sahithya Pravarthaka Co-operative Society Ltd; 2012.

2. Raveendran PP. Introduction. In: A Path and Many Shadows: Twelve Stories. New Delhi: Orient Blackswan; 2016.

3. Tharu Susie, Lalita K. Women Writing in India: The Twentieth Century. New Delhi: Oxford University Press; 1993. p. 324

4. Nair MTV. Ekanthapathika. In: Rajalakshmiyude Kathakal. Thrissur: Current Books; 2018.

5. Poole R. The Unknown Virginia Woolf. New York: Cambridge University Press; 1995.

6. Caramagno TC. The Flight of the Mind: Virginia Woolf's Art and ManicDepressive IIIness. United Kingdom: University of California Press; 1996.

7. Jamison KR. Touched with Fire: Manic -Depressive illness and Artistic Temperament. New York: Free Press; 1993.

8. Kaufman JC. The Sylvia Plath effect: Mental illness in Eminent Creative Writers. J Creat Behav. 2001 Jan; 35: 10.1002/j.21626057.2001.tb01220.x. [cited 2021 Aug 18]. Available from: https:// www.researchgate.net/publication/

298934728_The_Sylvia_Plath_effect_Mental_illness_in_eminent_cre ative_writes.

9. Lester D. Suicide as a Staged Performance. Comprehensive Psychology. 2015 Jan; 4: Doi: https://doi.org/10.2466/12.CP.4.18.

10. Devika J. Womanwriting=Manreading? New Delhi: Zubaan and Penguin Books; 2013.

11. Aparna S. Rajalakshmi and Virginia Woolf: Crossing Their Paths of Creativity. Res J Engl Lang Lit. 2019; 7 (1): 162-71. Available from: https://doi.org/10.33329/rjelal.7119.162.

12. Prabhu G. The disappearing act: Humanities in the medical curriculum in India. Indian J Med Ethics. 2019 July-Sep; 4(3): 194-7. Available from: https://ijme.in/articles/the-disappearing-acthumanities-in-the-medical-curriculum-in-india/?galley=html 